\title{
Study of Sustainable Development and its Implementation Path
}

\author{
Xuan Shen a, ${ }^{\star}$, Hao Wang ${ }^{b}$, Yan Shen ${ }^{c}$, Bo Li ${ }^{d}$ and Xi-lin Jiang ${ }^{e}$ \\ School of Economics and Management, Hubei Normal University, Huangshi, China \\ a419470093@qq.com \\ ${ }^{*}$ Corresponding author
}

Keywords: Sustainable development, Background, Essence, Implementation path.

Abstract. This paper analyses the background of the proposal of sustainable development in detail. The essence of sustainable development is revealed. The energy analysis method for sustainable development is presented. Some practical advices on the implementation of sustainable development are given. The work of this paper is of some help to the implementation of sustainable development.

\section{Introduction}

The global warming problem caused by the greenhouse gas emission has caused widespread concern around the world. In addition, conventional fossil energy, such as coal, oil, natural gas, is very limited and cannot meet the needs of development of human society. In this context, the world's effort to seek to accomplish sustainable development is gradually consensus [1].

Sustainable development is an economic growth model focused on long-term development, initially proposed at the United Nations Seminar on Human Environment held in Stockholm in 1972. In the report "Our Common Future" published in 1987, the World Commission on Environment and Development defined sustainable development as: that meets the needs of the present without compromising the ability of future generations to meet their needs [2].

Sustainable development is related to all aspects of human life, such as nature, environment, society, economy, technology, politics, and so on. On the angle of the natural attributes, sustainable development refers to the development mode that can protect and enhance the production capacity of the ecological environment and development updates. Ecologically, sustainable development is defined as "improve the quality of human existence while sustaining ecosystem assimilative capacity." Economically, sustainable development is defined as "the pursuit of maximizing net benefits of economic development while maintaining the quality of natural resources and the services provided." In terms of technology, sustainable development means the adoption of cleaner and more efficient technologies to accomplish maximum proximity 'zero emissions' or 'sealed' [3,4].

To sum up, sustainable development is a development model based on the coordination and common development of society, economy, population, resources and environment, and its purpose is to meet the needs of contemporary people, while not harming future generations' needs.

\section{Essence of sustainable development}

Specific contents about the theory of sustainable development involve the harmonization of sustainable economy, sustainable ecology and sustainable society. Topics include:

In terms of sustainable economic development, as economic development is the base of enhancing national strength and increasing social wealth, so sustainable development is not to cancel economic growth in the name of environmental protection but encourage economic growth. More attention should be paid to the quality of economic development rather than the amount of economic growth in the pursuit of sustainable development. To some extent, in the economical aspect, the intensive economic development mode should be employed in sustainable development. 
In terms of sustainable ecological development, sustainable development is required to achieve economic and social development within the capacity of nature, and should focus on the harmony with the carrying capacity of the nature. In the pursuit of economic and social development, the use of natural resources should be sustainable, and we must focus on protecting and improving the ecological environment. Ecologically sustainable development highly focuses on environmental protection, but different from the conventional model of development and environmental protection which can not be coordinated, sustainable ecological development requires to change the development mode to solve the environmental problems fundamentally.

In terms of sustainable society development: social equity is the key to sustainable development and the mechanism and objective of sustainable development. Among the whole system of sustainable development, economic sustainability is the foundation, ecological sustainability is the condition, and the society sustainability is the purpose. In the future process of human development, we should seek to realize a human-centered, sustained, stable and healthy development.

\section{Energy analysis method for sustainable development}

Ecosystems and socio-economic systems are mesh or chain systems coupled together by a plurality of nodes, material recycling, energy and information flows are fundamental characteristics of these two types of systems. Based on the characteristics of eco-systems and economic systems and laws of thermodynamics, Odum presented the energy analysis method with the core of energy. Energy analysis sets energy as a standard, it can measure and analyze the operating characteristics and development sustainability of the ecosystem or eco-economic system, by converting the energy of different types in the ecosystem or ecological economic systems into energy value of the same standard (usually the solar value) [5].

The basis of operational dynamics of the economic analysis of the ecological system from the perspective of energy analysis is energy transfer mode, speed and strength, which determines the allocation of factors of production, distribution, economic growth, the degree of environmental load, and resource depletion rate of productivity. Grasping the energy flux density into the system and transfer path is the basis of analysis of the evolution of the system's situation.

In terms of system sustainability analysis, energy analysis method has established a series of composite indicators reflecting ecological and economic efficiency of the energy value: net energy yield ratio(NEYR), energy investment ratio(EIR), environmental loading ratio(ELR), energy / money ratio, energy-based sustainability index(ESI).

\section{$\mathrm{ESI}=\mathrm{NEYR} / \mathrm{ELR}$}

As shown in the Eq. 1, ESI is the ratio of NEYR to ELR. If a country or region is of a high economic system energy rate and relatively low environmental loading rate, it is sustainable, and vice versa is not sustainable.

Energy accounting is a quantitative analysis technique that represents the value of resources, services and goods with the solar units (solar value) of production of monetary and non-monetary resources, services and commodities. Energy analysis can simultaneously measure the contribution of people and environment to the economic development, making up the defects of traditional monetary standard that the contribution of economic development can not be measured [6]. 


\section{The meaning of sustainable development}

First, the implementation of the sustainable development strategy can promote the ecological, economic and social unity.

Second, sustainable development can help to the transition of economic development from extensive to intensive mode, and coordinate economic development with population, resources and the environment. Extensive economy is an unsustainable economic development mode; and intensive economy takes into account the coordination of economic development with population, resources and the environment, thereby promoting sustainable economic development.

Third, it is conducive to the sustained, stable and healthy development, improve living standards and quality of the people. Sustainable development attaches great importance to social equity and harmony, sustainable economic growth and efficiency, and creates favorable conditions for socio-economic sustainablity, stable and healthy development, thus achieving harmony and coordinated development between people and the environment, people and society.

Finally, sustainable development is to promote the long-term interests, the interests of the whole development, and promote the non-material resources or information resources (technology and knowledge) development, therefore, under the conditions of sustainable development, increasing the cost of the ecological environment, human resources costs $\mathrm{R} \& \mathrm{D}$ costs and the cost of investment in science and technology, social responsibility is worth it.

\section{Effective path to the realization of sustainable development}

\section{Improve strategy inspection and supervision system for sustainable development}

Further improve the regulation system for the sustainable development, strengthen the sustainable development strategy inspection, supervision and provide a legal basis for the sustainable development strategy. Strengthen sustainable development law enforcement agencies and law enforcement team building, improve the ability of law enforcement to provide a reliable guarantee for the implementation of laws and regulations of the sustainable development.

\section{Attach great importance to the role of science and technology}

Knowledge innovation and technological progress have provided new technologies for the understanding and control of environmental pollution. Knowledge innovation and technological progress can help to cultivate people's environmental awareness, solve the problem of concept of sustainable development.Scientific and technological progress is an effective way to improve the service efficiency of resource and develop new resources.

\section{Strengthen domestic and international exchanges and cooperation}

Strengthen international exchanges and cooperation, actively learn from the advanced experience of foreign countries. China wants to carry out extensive exchanges and cooperation with developed countries and developing countries in various fields related to sustainable development, in order to take advantage of advanced science and technology of the contemporary world and absorb successful experience of other countries in the implementation of the sustainable development strategy.

\section{Summary}

This paper analyses the background of the proposal of sustainable development in detail, and then reveals the essential nature of sustainable development. Finally, some suggestions on the implementation path of sustainable development are given. The work of this paper can be of some useful help to the successful implementation of sustainable development. 


\section{Acknowledgement}

This research was financially supported by The National Natural Science Foundation of China "Humanities and Social Sciences in 2015 the Ministry of Education Youth Fund project Dependent regression models and the diffusion process of statistical inference and its application"(1147 1105), the annual social project of 2015 of Association of Social Science Research of Huangshi City "Research of Local Fiscal Expenditure Structure Optimization - A Case Study of Huangshi"(HSSK2015B1121), Humanities and Social Sciences in 2015 the Ministry of Education Youth Fund project "Agricultural support policy enforcement mechanism research".

\section{References}

[1] Lele S M, Development W, Coomes O T. Sustainable development: A critical review[J]. World Development, 1991, 19(91):607-621.

[2] Bruntland G. Our common future: The World Commission on Environment and Development[J]. Environment, 1987, 29(5):25-29.

[3] United Nations. Department for Policy Coordination and Sustainable Development. Indicators of sustainable development framework and methodologies[C]// Commission on Sustainable Development. United Nations 1996.

[4] United Nations. Department of Economic. Indicators of Sustainable Development: Guidelines and Methodologies[J]. United Nations Division for Sustainable Development Department of Policy Coordination \& Sustainable Development, 2001.

[5] Turton H, Moura F. Vehicle-to-grid systems for sustainable development: An integrated energy analysis[J]. Technological Forecasting \& Social Change, 2008, 75(8):1091-1108.

[6] Unander, Fridtjof. Energy indicators and sustainable development: The International Energy Agency approach[C]// Natural Resources Forum2005:377-391. 